\title{
BIOFOULING REDUCTION FOR IMPROVEMENT OF DEPTH WATER FILTRATION. FILTER PRODUCTION AND TESTING
}

\author{
Ewa Sztuk - Sikorska, Leon Gradon* \\ Warsaw University of Technology, Faculty of Chemical and Process Engineering, \\ ul. Warynskiego 1, 00-645 Warsaw, Poland
}

\begin{abstract}
Water is a strategic material. Recycling is an important component of balancing its use. Deep-bed filtration is an inexpensive purification method and seems to be very effective in spreading water recovery. Good filter designs, such as the fibrous filter, have high separation efficiency, low resistance for the up-flowing fluid and high retention capacity. However, one of the substantial problems of this process is the biofouling of the filter. Biofouling causes clogging and greatly reduces the life of the filter. Therefore, the melt-blown technique was used for the formation of novel antibacterial fibrous filters. Such filters are made of polypropylene composites with zinc oxide and silver nanoparticles on the fiber surface. These components act as inhibitors of bacterial growth in the filter and were tested in laboratory and full scale experiments. Antibacterial/bacteriostatic tests were performed on Petri dishes with E. coli and B. subtilis. Full scale experiments were performed on natural river water, which contained abiotic particles and mutualistic bacteria. The filter performance at industrial scale conditions was measured using a particle counter, a flow cytometer and a confocal microscope. The results of the experiments indicate a significant improvement of the composite filter performance compared to the regular fibrous filter. The differences were mostly due to a reduction in the biofouling effect.
\end{abstract}

Keywords: bacteria, filtration, particle, process design, water

\section{INTRODUCTION}

The demand for water is growing rapidly among increasing world populations. This causes the world to turn to water reclamation and reuse. The investment in treatment technologies requires developing new products or optimizing current techniques that are already known to meet a high-quality freshwater demand (USEPA, 2004). The deep-bed filtration technique is one of the most effective available water purification methods. The production of either granular or fibrous filters is simple and inexpensive. The use of high pressure pumping systems is not required. The main problem with water purification processes is that the feed stream is organically and permanently loaded. Organic matter filtration is often associated with operational problems, such as loss of flux and shortening of filter life (Williams and Edyvean, 1998). Because contamination removal is accomplished by particle deposition throughout the filter medium, the method can be improved by optimizing the filter structure, porosity and collector diameter (Ochi and Vernoux, 1999). Alternatively, material modifications can be performed to obtain antibacterial or bacteriostatic properties in the fibers (Nowak et al., 2014). At present, granular filters made only of activated carbon are able to tackle bacteria growth problems. However, the relatively large pore sizes reduce their ability to stop smaller particles (Camper et al., 1985). Fibrous filters that are produced in the melt-blown technology process are theoretically able to stop particles as small as bacteria. Filter effectiveness depends on the polymer material and can be used over a wide range of 
applications. Different fibrous structures, such as mono-, homogeneous over the entire volume, and multilayer (composed of layers varying in porosity or fiber diameter), are manufactured and used for specific purposes. Biofouling still remains an unsolved problem.

Both literature (Selomulya et al., 2005) and our own findings (Fig. 1) show that the front surface of the outer fabric adsorbs most contaminations. If the deposit contains bacteria, e.g., in a growth phase, clogging of the filter occurs, not only from the up-flowing contamination but also from multiplying bacteria.
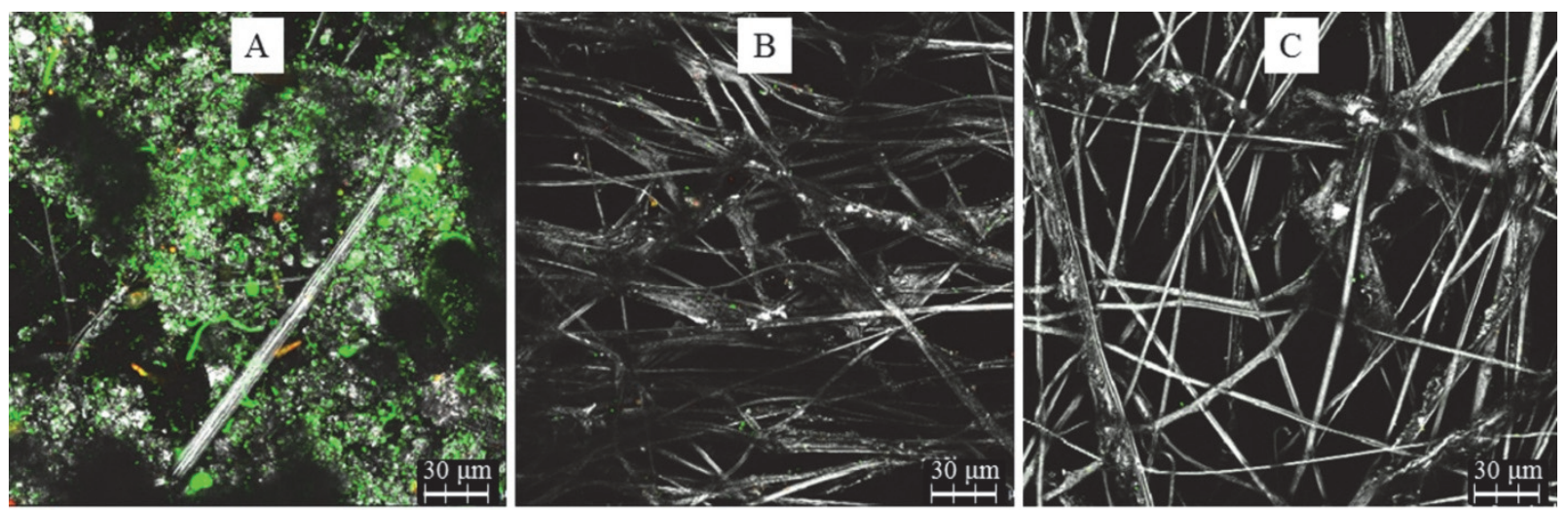

Fig. 1. CLSM images of a fibrous filter tested on natural river water;

A - outer layer, B - $1 \mathrm{~mm}$ deep, C - $5 \mathrm{~mm}$ deep

Proper antibacterial modifications of the polymer surface can reduce the biofouling effect, extend filter longevity and make the filtrate free of bacterial contamination. To accomplish this goal, it is necessary to create an effective method to modify the fibrous surface and then analyze the performance of modified filters.

In this study, a production method of antibacterial fibrous filters is proposed. The performance of standard filters made from polypropylene was compared with polypropylene filters modified with zinc oxide $(\mathrm{ZnO})$ and silver $(\mathrm{Ag})$ nanoparticles. Antibacterial tests were performed in both laboratory and industrial scale experiments. The results are presented and summarized in conclusions.

\section{MATERIALS AND METHODS}

\subsection{Particle and bacterial motion and deposition}

In the deep bed filtration process, contaminations are removed by granular or fiber particle deposition throughout the filter medium (Tien, 2012). Particles deposit on these collectors via different mechanisms: inertial impaction, interception, sedimentation, electrostatic forces, Brownian diffusion, and straining. In addition, deposition may also result from chemotaxis and detachment (Tien and Ramarao, 2011). The dominant mechanism depends on many parameters, such as fluid flow, particle and fabric properties (Fig. 2).

The trajectory of motion for solid particles inside a fibrous structure can be characterized by welldefined equations resulting from the force balance acting on the particle. Bacterial movement depends on their type because some bacteria, such as Methylibium petroleiphilum, exhibit motility. The selfinduced random movement of motile microbes, mostly caused by flagella, is known as chemotaxis (Berg and Brown, 1972). Non-motile bacterial movement is similar to that of abiotic particles. 


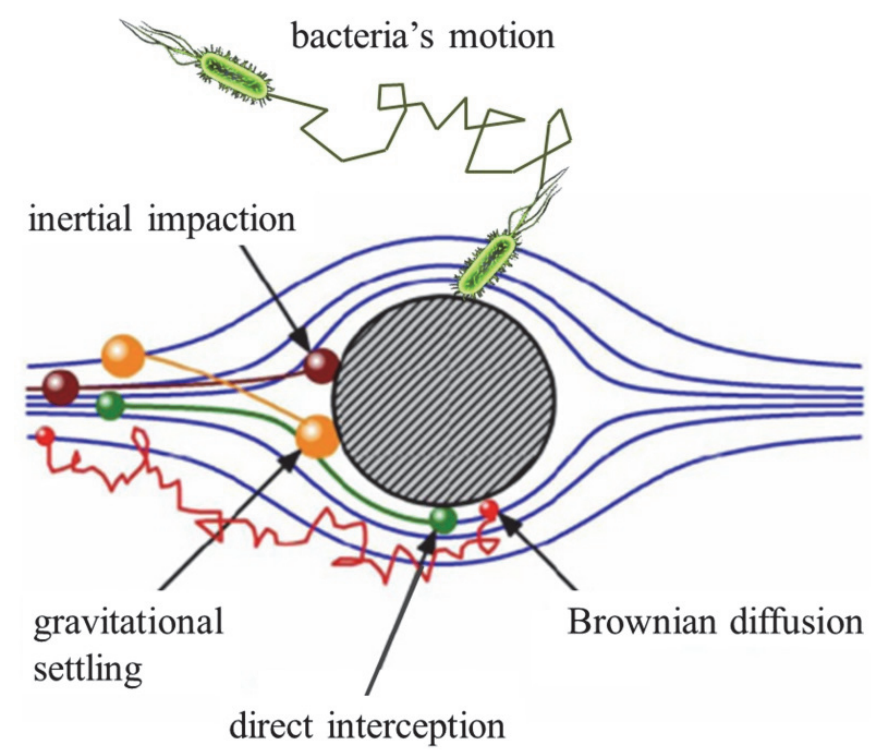

Fig. 2. Movement of bacteria and solid particles near the fiber

However, there are no practical field applications of bacterial removal by fibrous filters. Although some authors have tried to model the deposition of particular bacteria types (Gac and Gradon, 2015), their calculations are based on idealistic assumptions. In fact, almost every feed stream contains more than one type of bacteria. Many studies state different deposition mechanisms, even for the same strain of bacteria, e.g., E. coli D21 and E. coli D21f2 (Ong et al., 1999). Therefore, because there is a lack of comprehensive data for all conditions, it is hard to predict the behavior of many bacterial strains in the natural environment. In this work, the filtration efficiency of bacteria in natural river water was counted based on their total amount, without distinguishing their type.

The initial filter porosity decreases when particles or bacteria are deposited on the fibers. Filtration efficiency and pressure drop changes over process time. Filter loading causes an increase in the flow shear stress inside of the filter pores. Consequently, there is a temporary decrease in filtration efficiency because deposited matter is re-entrained when it is displaced into deeper parts of the filter and further to the filtrate. Increased loading for a stream of suspension through the filter also leads to increase of the pressure drop.

The pressure drop profile in a filter during loading time is directly related to the process economy. The main operating cost $(M)$ is the expenditure of energy for pumping suspensions through the filter at a particular flow rate $(Q)$. During filtration time $\left(t_{F}\right)$, this cost can be calculated as:

$$
M=\int_{0}^{t_{F}} \frac{c_{P E} \cdot Q \cdot \Delta p(t)}{\eta_{P}} d t
$$

where $c_{P E}$ is the unit price energy, $\eta_{p}$ denotes the mechanical efficiency of the pump, and $\Delta p(t)$ is the momentary pressure drop across the filter.

The energy consumption for filtration is directly connected to the pressure drop. This is the case for a fixed price of electricity $\left(c_{P E}\right)$, the value of $Q$ and the pump quality:

$$
M=\frac{c_{P E} \cdot Q}{\eta_{P}} \int_{0}^{t_{F}} \Delta p(t) d t
$$

Therefore, the initial filter structure (i.e., porosity and fiber diameter) determines the evolution of the pressure drop and filtration efficiency during loading, as well as the economy of the process. The values of $M$ and filtration efficiency (during filter exploitation time) define the usefulness of any filter. 


\subsection{Formation of a deep-bed filter structure modified with $\mathrm{ZnO}$ and $\mathrm{Ag}$}

The development of low-pressure filtration technologies poses a new challenge. This technology requires the production of filter materials (e.g., composite filters) containing antibacterial substances on the material surface.

The advanced melt-blown technique is the most promising method for fiber production (Gradon et al., 2005; Podgorski et al., 2006). Given proper process controls, the direct introduction of desired antibacterial nanoparticles towards a fiber surface during a standard fiber formation process is enabled (Bodasinski et al., 2015).

Water bacteria are very diverse organisms. To date, no universal antibacterial chemical has been found. However, the antibacterial properties of $\mathrm{ZnO}$ and $\mathrm{Ag}$ nanoparticles are known and have been verified by many researchers (Andrade et al., 2015; Mg et al., 2013). They can act on different organisms (You et al., 2013) and, as a result, are used in various combinations to create a filter that would exhibit antibacterial properties over a broad range of bacteria types. Our laboratory experiment confirms an enhancement of inhibition of bacteria growth at simultaneous presence of $\mathrm{ZnO}$ and $\mathrm{Ag}$ nanoparticles on the fiber surface.

In this study, 2 multilayer filters made of pure polypropylene and a composite of polypropylene, $1 \%$ vol $\mathrm{ZnO}$ and $0.1 \%$ vol $\mathrm{Ag}$ nanoparticles, were produced using the melt-blown technology process. Both were made under the same production parameters. This ensured that gradient filters were obtained. The multilayer filters were characterized by their porosity range from $70-92 \%$ and average fiber diameter of 26.8-1.3 $\mu \mathrm{m}$, changing with the flow direction. The filtration efficiency of solid particles above $1 \mu \mathrm{m}$ for these 2 filters was measured by a particle counter LiQuilaz S02 of Particle Measuring Systems, Inc. The efficiency ranged from 95 to $99 \%$ during the standard filtration process and the initial pressure drop on the fabrics was approximately 0.6 bar.

A schematic of the stand for producing fibers by blowing a melted polymer is shown in Fig. 3.

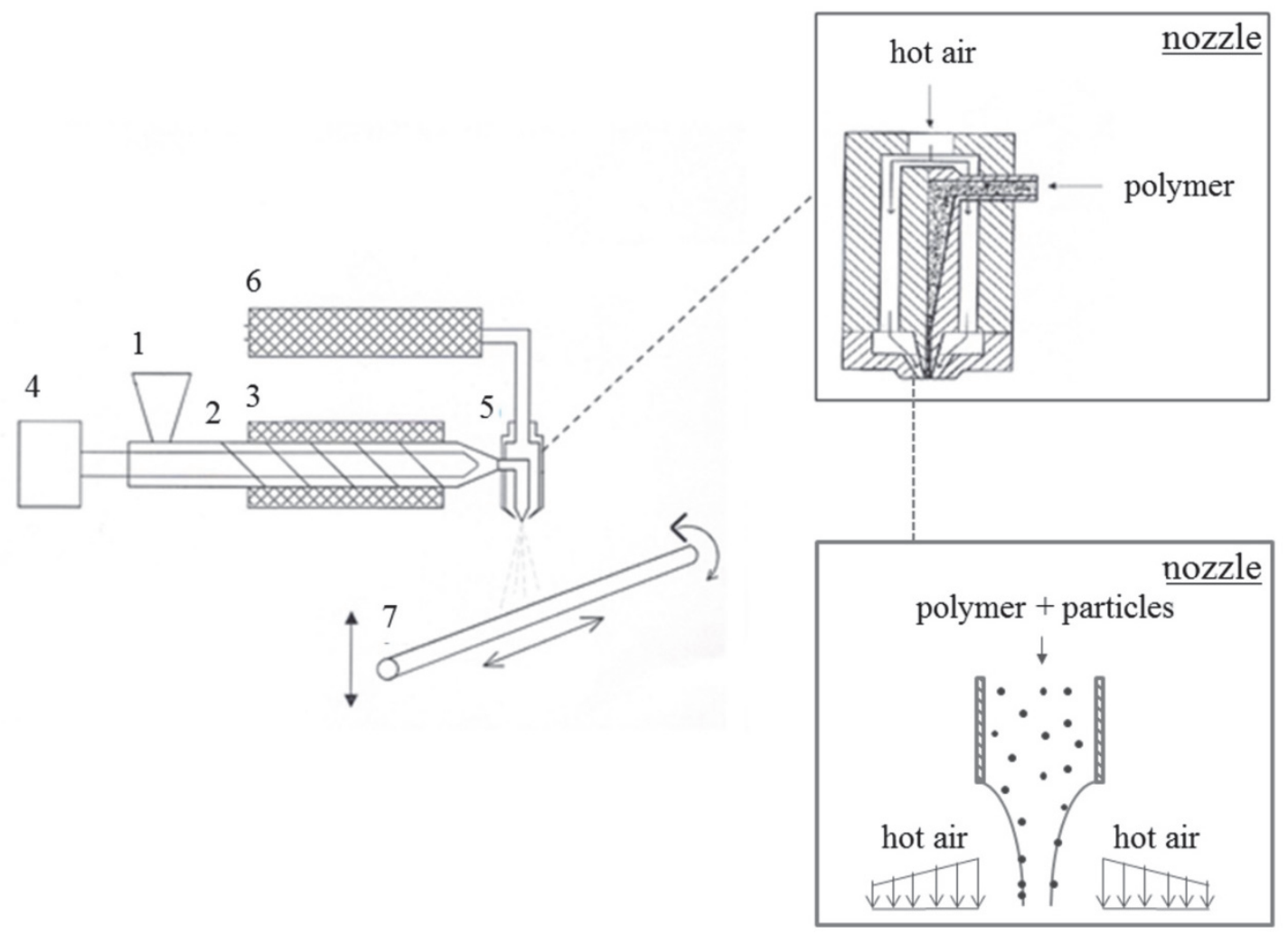

Fig. 3. Production of fibrous material in the melt-blown technique (Gradon et al., 2005) 
The granulated polymer is poured into the container (1). An extrusion screw (2) transports the polymer. The extruder is externally heated by an electric heater (3) over a few zones. The temperature in the zones must be precisely controlled. The polymer is melted and homogenized during extrusion. The extruder screw is driven by an electric motor with a gear system (4). The polymer, which is homogenized and melted, is pressed into a die (5). The die is heated with hot air supplied from a compressor and air heater (6). The melted polymer is extruded through a row of nozzles. Air nozzles surround the polymer nozzle. A stream of hot air extends the polymer filaments under the nozzle and form thin fibers. The fibers are collected on the pivot with cores (7). The pivot rotates and moves backand-forth to form a proper cartridge filter structure.

During the process, a filter is made from a granulated polymer in one simple manufacturing stand. The control of the process parameters, such as polymer and air flow rates, temperatures of both media, and the distance between the die and the fiber collector, enables the production of filters with the desired morphology. The morphology is determined by fiber diameter and fiber packing density in the filter structure.

A new composite filter was produced for testing the effect of reducing biofouling. The surface of the filter was modified with $\mathrm{ZnO}$ and $\mathrm{Ag}$ nanoparticles. The filter raw material was granulates of polypropylene, with an appropriate concentration of nanoparticles in the mixture.

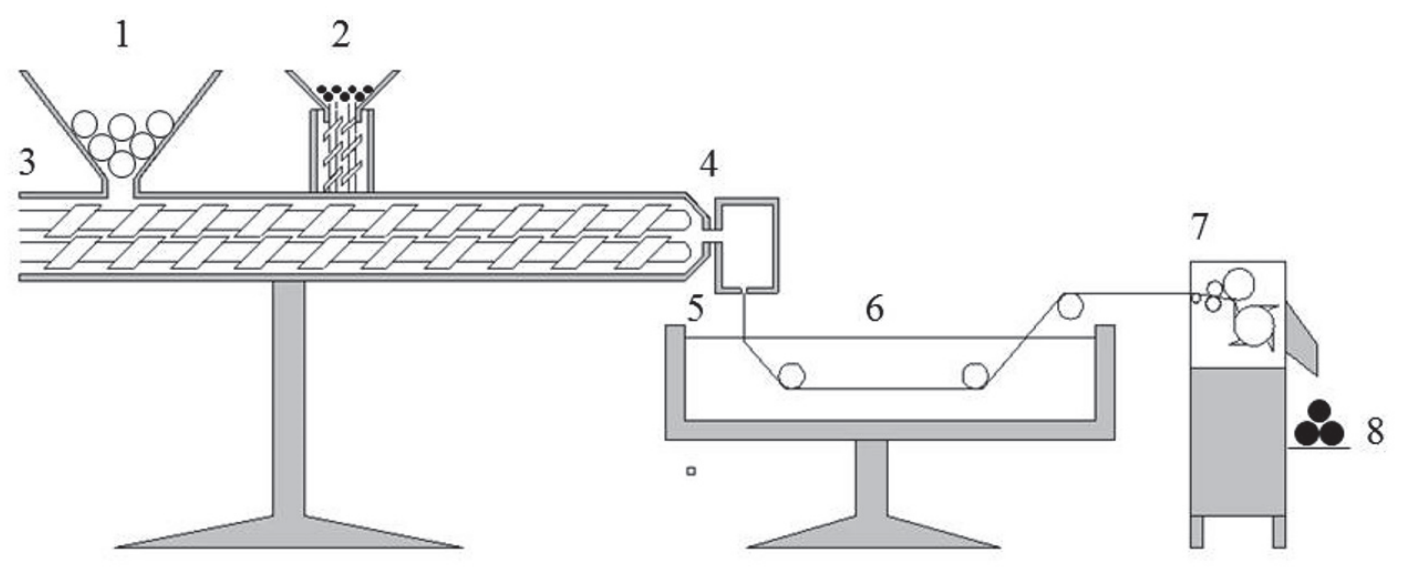

Fig. 4. Production of polypropylene composite with $\mathrm{ZnO}$ and $\mathrm{Ag}$ nanoparticles

Granulates used in the mixture are produced in the technological system shown in Fig. 4. Granulates of pure propylene (1) are introduced into the twin-screw extrusion cylinder (3), which is then melted and transported into another section of the extruder. The powder consisting of a uniform mixture of $\mathrm{ZnO}$ and $\mathrm{Ag}$ particles (2) is batched in a controlled amount into the extruder, mixed with the melted polypropylene and transported to the die (4). Here, the monofilament (5) is formed. The monofilament has a uniform mixture of nanoparticles. After cooling in the water bath (6), it is introduced to the rotating knife system (7) where granules (8) are produced. Granules of polypropylene that consist of $\mathrm{ZnO}$ and $\mathrm{Ag}$ nanoparticles with a $4 \%$ mass concentration, are used as raw material for the production of the composite filters using the melt-blown technique.

The final concentration of nanoparticles in polypropylene used for filter production is controlled by diluting the concentrated granulates with pure polypropylene granulates. The values of $1 \% \mathrm{vol} \mathrm{ZnO}$ and $0.1 \% \mathrm{vol} \mathrm{Ag}$ of nanoparticle concentration in polymer are sufficient to obtain antibacterial/bacteriostatic effects, as shown below.

The procedure for filter cartridge formation is the same as the production of regular polypropylene filters as described above. During fiber formation in the nozzle at the die (Fig. 3), in the case of 
a mixture of particles with polypropylene, the particles are transported to the surface of the fiber during fiber formation in the nozzle of the die (Fig. 3). This occurs due to the stress effect at the surface of the yet melted fiber. After polymer solidification, the particles are strongly tied with the fibers (Fig. 5). The lower the fiber diameter, the higher the number of nanoparticles located on the outer surface of the fibers.

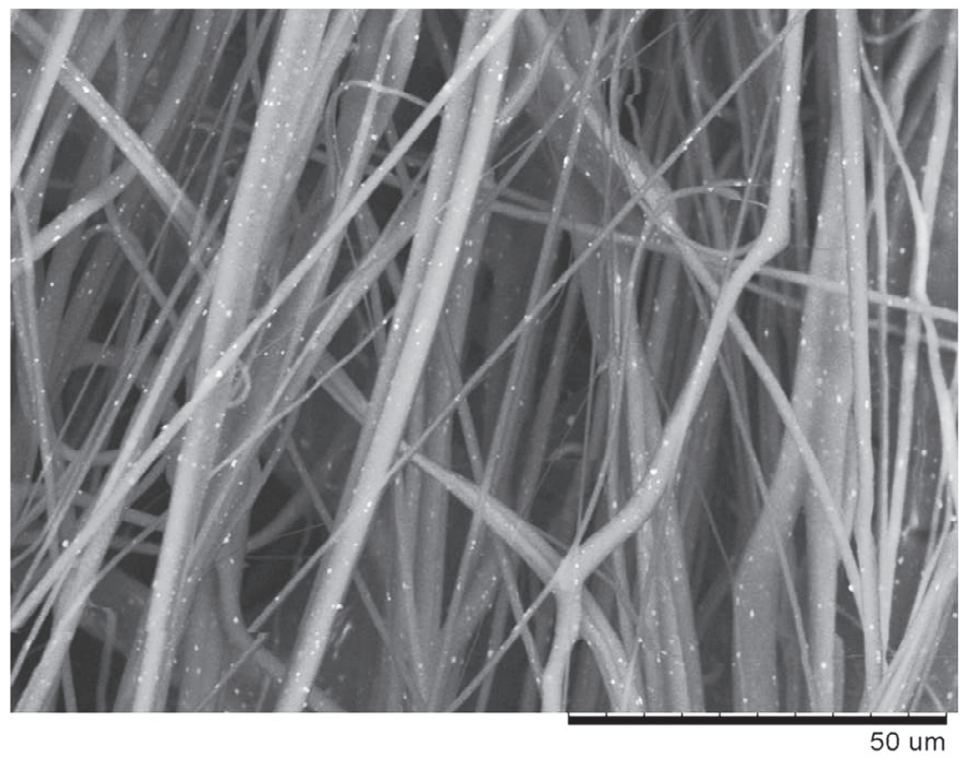

Fig. 5. SEM Image of modified filter with $\mathrm{ZnO}$ and $\mathrm{Ag}$ nanoparticles (bright spots)

\subsection{Antibacterial/bacteriostatic tests}

Because the bacterial environment is extremely diverse, an antibacterial and bacteriostatic test was performed on common bacterial strains in the aqueous environment. E. coli and B. subtilis were chosen as representatives of gram-negative and gram-positive bacteria, respectively. The tests were carried out on Petri dishes. The E. coli was grown in a differentiating medium, while the $B$. subtilis was grown in $1 \%$ Luria-Bertani agar (LB). In the case of both fabrics (the non-modified polypropylene filter fabric and the filter modified with $\mathrm{ZnO}$ and $\mathrm{Ag}$ nanoparticles), samples were taken from the exterior, 1/3, 2/3 depth and interior of the filter structure. It has to be emphasized that each sample was differing in fiber diameter. The fiber diameters were decreasing with the flow direction. Each sample was held at $37^{\circ} \mathrm{C}$ for $24 \mathrm{~h}$. Results discussed below show the antibacterial and bacteriostatic properties, which are reflected by the halo around the fabric samples. The preliminary positive effect of biofouling at the local parts of the filter layers makes allowances for testing the modified filter under real filtration conditions.

\subsection{Bacterial filtration tests}

Ten-inch long cartridge filters, with the external diameter of $65 \mathrm{~mm}$ and the internal diameter of $35 \mathrm{~mm}$ (Fig. 6), were tested in conditions typical for water filtration. Filters made of polypropylene and its composite with $\mathrm{ZnO}$ and $\mathrm{Ag}$ nanoparticles were fabricated in the melt-blown technology process. It is emphasized that these filters are regular absolute filters as defined by international standards.

Filtration experiments were carried out using Chriesbach (Dubendorf, Switzerland) river water. The average water quality was characterized as having a turbidity of $1.3 \pm 0.2 \mathrm{NTU}$ and a temperature of $12.7^{\circ} \mathrm{C}$. The amount of bacteria per milliliter of river water was a constant during the experiments, at approximately 700,000 of total bacteria, and 550,000 live bacteria in the flow-through buffer tank. 
Biofilms grown on the Chriesbach water surface were analyzed using the amplicon pyrosequencing. It contained substantial amounts of the following bacterial species (with a relative abundance $>2 \%$ ): Niastella sp., Arcicella sp., Acidobacterium sp., Devosia insulae, Bradyrhizobium sp., Reyranella massiliensis, Maricaulis sp., Agrobacterium tumefaciens, Methylibium petroleiphilum, Sphaerobacter sp., Rhodoplanes sp., Giesbergeria sinuosa, Acidovorax sp., and Desulfomicrobium orale, Chondromyces sp. All these bacteria are gram-negative and some are motile
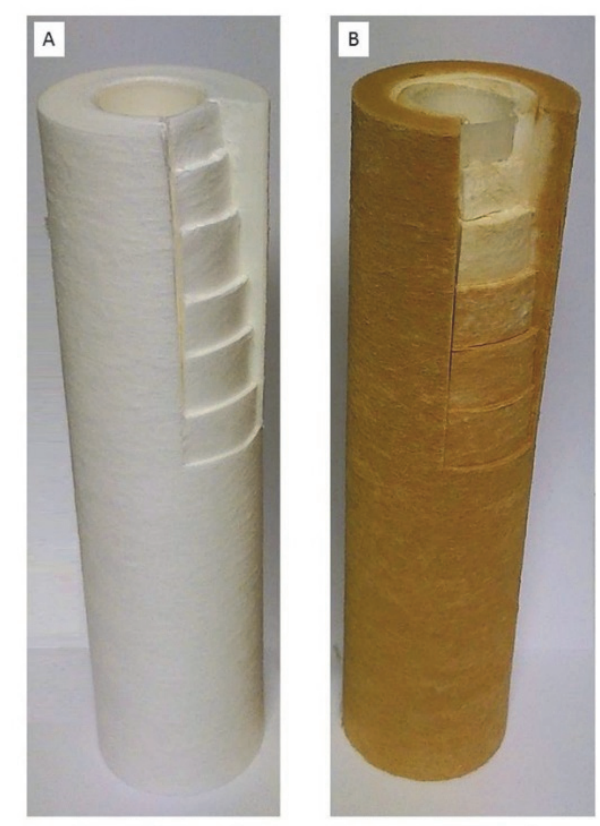

Fig. 6. Filter for testing; A - clean filter, B - filter loaded with solid contamination

A diagram of the filtration set-up is schematically shown in Fig. 7. The filters were tested under nominal flow conditions of $600 \mathrm{l} / \mathrm{h}$. The experiments were carried out until a 2.5 bar pressure drop on the filter was reached. This critical value commercially indicates the clogging of filter pores, which leads to a rapid pressure drop and filter damage.

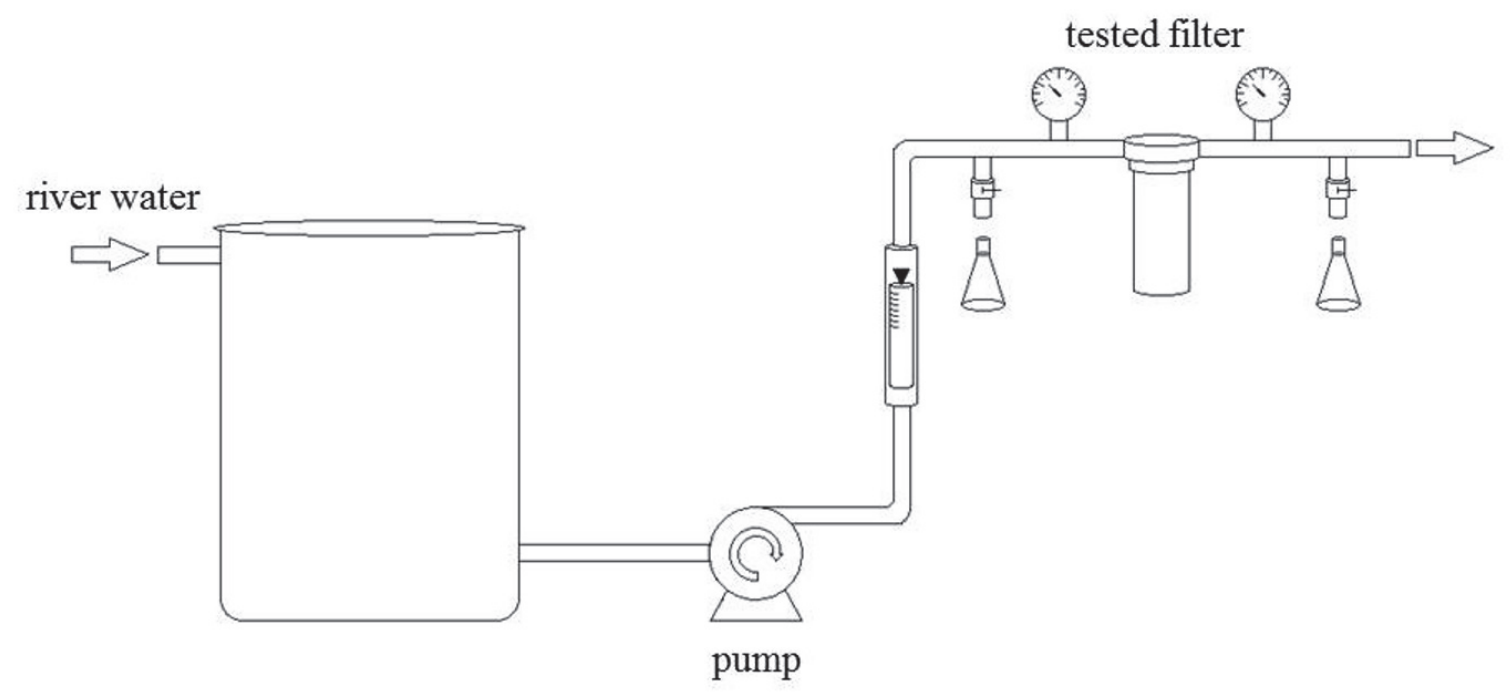

Fig. 7. Diagram of the experimental set-up 
During the experiments, the following parameters were measured: the pressure drop on the filter, and the number of bacteria upstream and downstream of the filter. The number of bacteria deposited or grown/killed on the fibers was determined based on the difference between the quantities upstream and downstream of the filter. The amounts of total and live cells were counted separately and determined using flow cytometer CyFlow Space, Sysmex Partec GmbH. SYBRR Green and Propidium Iodide (diluted 100 times in DMSO) were used, respectively, according to literature (Van der Merwe et al., 2014). The number of dead bacteria was determined as the difference between the total and the live cells.

\section{RESULTS AND DISCUSSION}

The data presented below show that the polypropylene and polypropylene composite (with $\mathrm{ZnO}$ and $\mathrm{Ag}$ nanoparticles) filters had a different performance.

Plate tests on the E. coli and B. subtilis, presented in Fig. 8, confirmed the antibacterial properties of $\mathrm{ZnO}$ and $\mathrm{Ag}$ nanoparticles. The clear zone, which is visible only around the modified material, shows inhibited growth. This suggests that bacteria did not grow near the fibers. The same zone is wider for $B$. subtilis. In the case of E. coli, a bacteriostatic effect can be noticed instead.
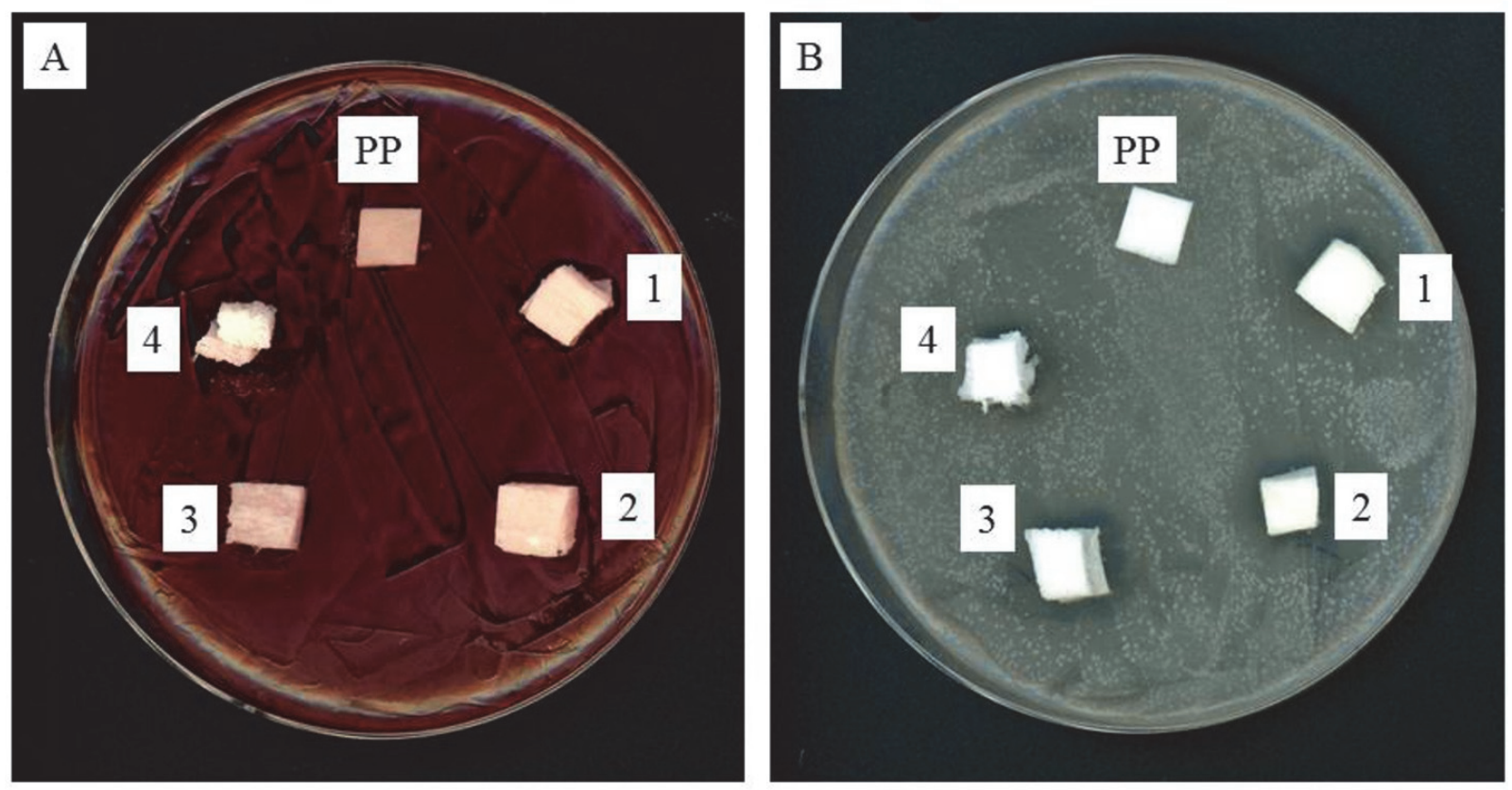

Fig. 8. Antibacterial and bacteriostatic plate test; A - on E. coli on differentiating medium incubated for $24 \mathrm{~h}$ at $37^{\circ} \mathrm{C}$, B - on B. subtilis on LB medium incubated for $24 \mathrm{~h}$ at $37^{\circ} \mathrm{C}$. $\mathrm{PP}$ - pure polypropylene.

$1,2,3,4$ - layers of modified fabric starting from the filter's inlet

The antibacterial action mechanisms of $\mathrm{ZnO}$ and $\mathrm{Ag}$ are still not fully understood. Some maintain that their properties are mainly associated with ion diffusion. Others claim that their toxic effect is the result of direct contact between bacteria and the nanoparticles (Andrade et al., 2015; Mg et al., 2013). Based on our experiments, it is hard to define which mechanism was dominant.

Industrial-scale experiments conducted on natural river water, which was contaminated by many types of bacteria, also showed a performance improvement. The results shown in Figs. 9-10 indicate that both pressure drop and the inhibition of bacterial growth are significantly affected by the implementation of 
$\mathrm{ZnO}$ and $\mathrm{Ag}$ nanoparticles to the fiber surface. The process filtration efficiency of $1 \mu \mathrm{m}$ solid particles and larger was previously defined in the range of $95-99 \%$. Because both filters exhibited expected separation efficiencies in the full range of the filtration time, our interest was focused on the economic aspect of the process. The lifespan of the filter and the profile of the pressure drop were the main factors defining economics.

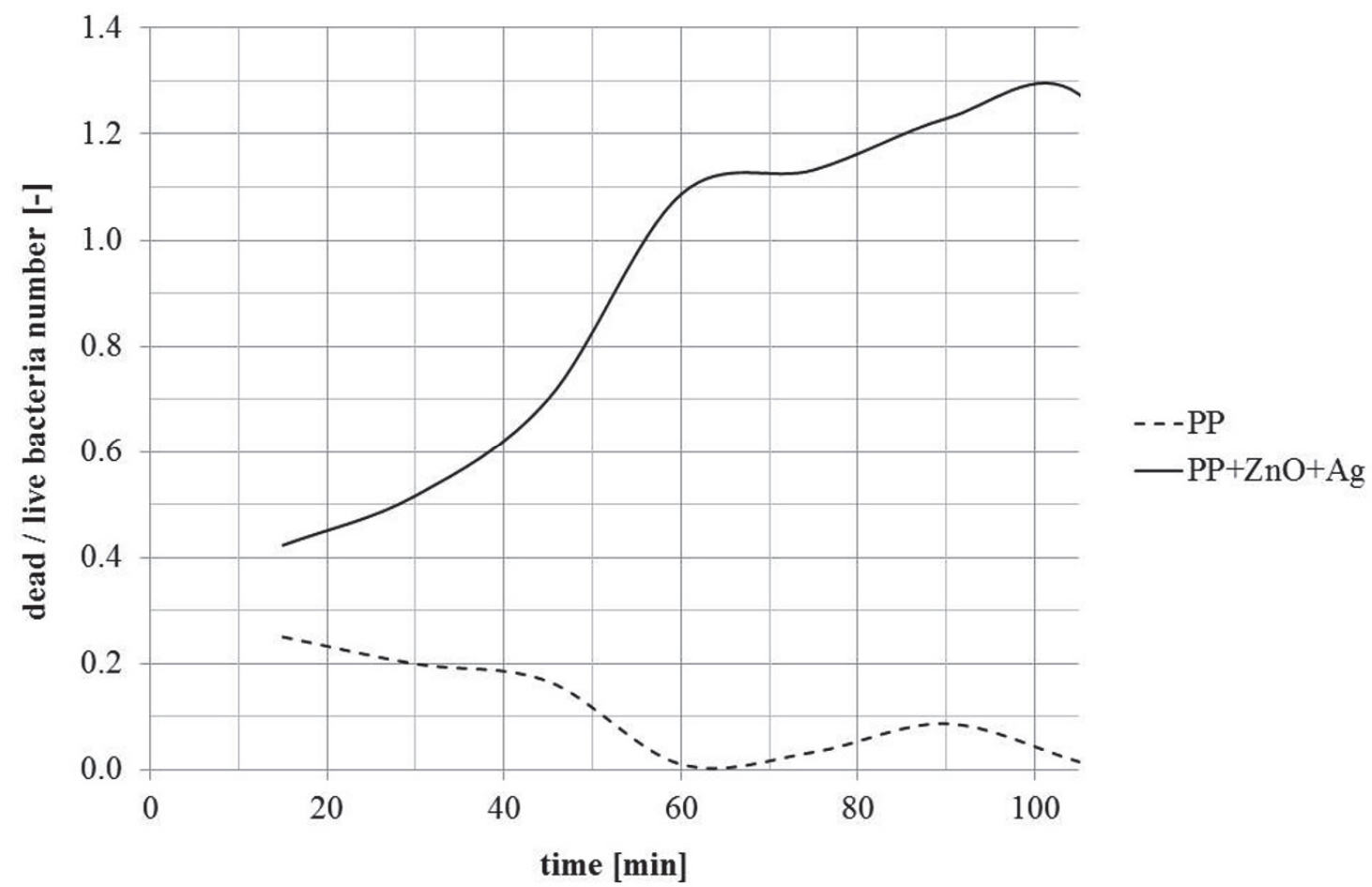

Fig. 9. Relationship between the number of dead and live bacteria captured during the filtration process for standard (PP) and modified filters with $1 \%$ zinc oxide and $0.1 \%$ silver nanoparticles $(\mathrm{PP}+\mathrm{ZnO}+\mathrm{Ag})$

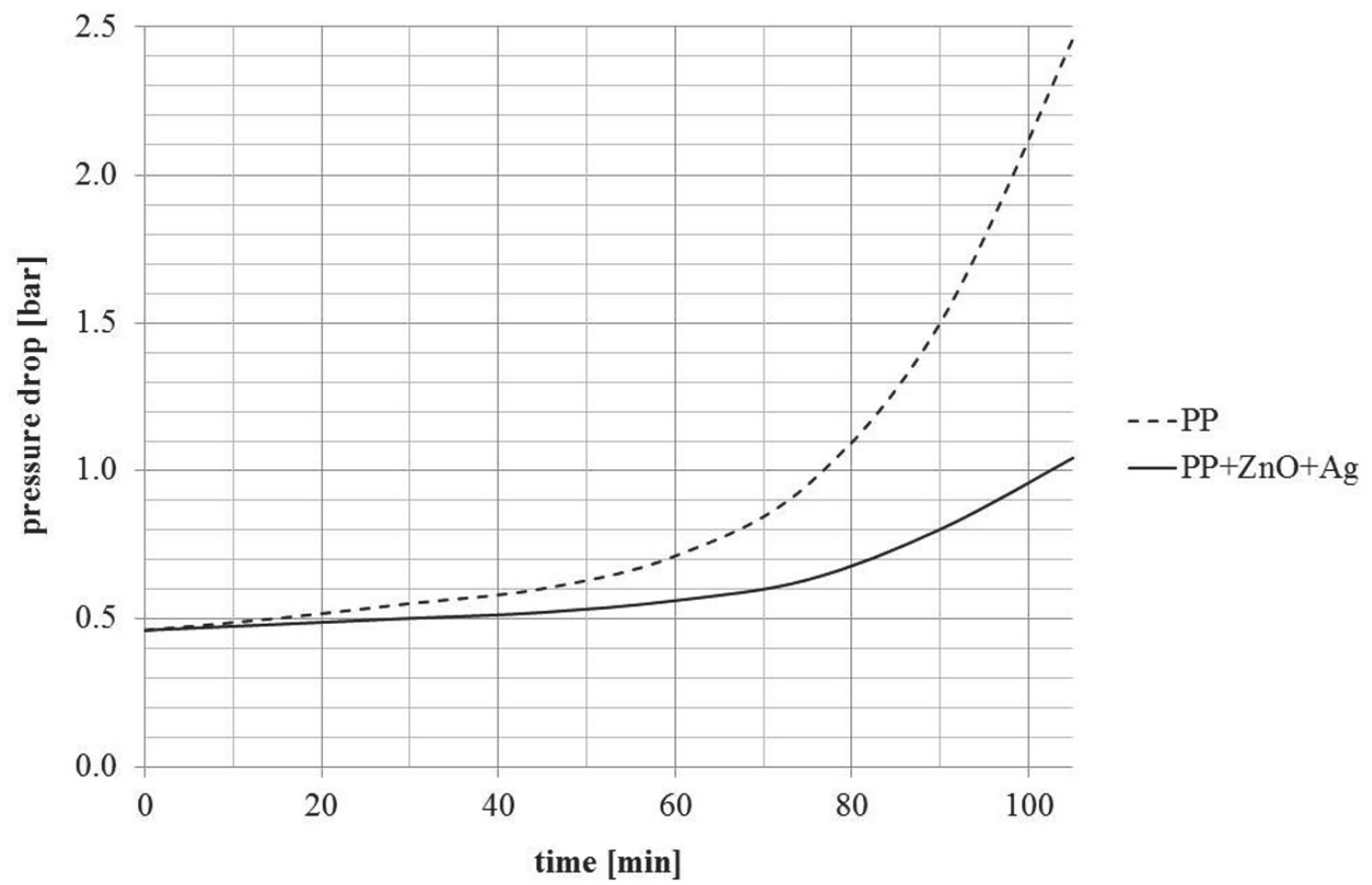

Fig. 10. Pressure drop on the filter during filtration process for standard (PP) and modified filters with $1 \%$ zinc oxide and $0.1 \%$ silver nanoparticles $(\mathrm{PP}+\mathrm{Ag}+\mathrm{ZnO})$ 
Fig. 9 describes the ratio between the number of dead and live bacteria as separated by the filters. This proportion declined for the standard polypropylene filter and the amount of live bacteria captured by the filter was higher compared to the removal of dead bacteria. The composite filter separation properties developed differently. The ratio between the filtrated dead and live bacteria increased during the process. After some time, the proportion reversed, indicating that the amount of dead bacteria stopped by the filter was higher than the removal of live bacteria. The number of bacteria upstream was constant. Therefore, the growing number of dead bacteria, which accumulated on the fibers, along with the decrease in living bacteria, must be the consequence of bacteria killing. The initial pressure drop on the filter is equal for both filters because they have the same fibrous structure, porosity and fiber diameter. After a short filtration time, the suspended contamination deposits on the previously deposited matter, and creates agglomerates. At this point, non-steady state filtration starts. The initial porosity decreases with time. Initially, it refers to a clean fibrous fabric, but after a short time, filter pores build over with deposited particles, thereby changing the porosity of the filtrating structure. In addition, the deposited bacteria start to reproduce, which also affects the pore sizes. This growth increases especially when microorganisms deposit on solid surfaces. Because these are fixed cultures, they are less strongly affected by changes in environmental conditions (Lazarova and Manem, 1995). Consequently, the resistance for the flowing fluid increases, as shown in Fig. 10. At the same time, the growth for the composite filter is slower. This may be the effect of $\mathrm{ZnO}$ and $\mathrm{Ag}$ nanoparticle supplementation. The natural river water flowing in the riverbed with the velocity over $0.4 \mathrm{~m} / \mathrm{s}$ contains bacteria at different stages of growth kinetics. $\mathrm{ZnO}$ and $\mathrm{Ag}$ nanoparticles located on the fiber surface inhibit the growth of bacteria. If fewer bacteria are reproduced, the clogging of the filter results only from the upflowing contamination. Porosity changes are less rapid.

Taking Eq. 2 into account, the ratio $m$ of the costs of water pumping through both, modified $(\mathrm{PP}+\mathrm{ZnO}+\mathrm{Ag})$ and non-modified $(\mathrm{PP})$ filters, can be calculated as:

$$
m=\frac{\left[\int_{0}^{t_{F}} \Delta p(t) d t\right]_{P P+Z n O+A g}}{\left[\int_{0}^{t_{F}} \Delta p(t) d t\right]_{P P}}
$$

Comparing the effect of filter loading, the value of $t_{F}$ is defined at the moment when one of the filters reaches the pressure drop of 2.5 bar. In this work, it was $105 \mathrm{~min}$ for the non-modified filter.

The calculated results based on the $\Delta p(t)$ profiles (Fig. 10) give the value of $m$ equal to 0.68 . This means that the cost of pumping for the modified filter versus the regular filter reduced by $32 \%$. Taking into account the profile of the curve for composite fibers (Fig. 10), the lifetime of this filter, for reaching the nominal $\Delta p=2.5 \mathrm{bar}$, is expected to be much longer than that of pure PP filter.

\section{CONCLUDING REMARKS}

The melt-blown technology, which is equipped with a twin-screw extruder, is able to produce fibrous filters with antibacterial nanoparticles located on the surface. The bacteriostatic effect reduces the biofouling effect at the outer surface of the filter.

Even small concentrations of the antibacterial compounds (1\%vol $\mathrm{ZnO}$ and $0.1 \% \mathrm{vol} \mathrm{Ag}$ nanoparticles) greatly increased the working time of the filter. Therefore, the cost of the filtration process was significantly reduced, while the expenses on the filter material production increased just by a few percent. Most significantly, these composite filters improved bacterial removal, although total removal was not achieved. Nevertheless, it should be taken into consideration that $\mathrm{ZnO}$ and $\mathrm{Ag}$ nanoparticles do not exhibit antibacterial activity for every bacterial type. Further tests investigating the leaching speed would deepen our understanding of the process mechanism. One of the effects which should be 
considered is related to the destroying of bacteria due to shear-stress effect resulting from the suspension flow through the filter structure. The development of a production method for antibacterial composite fibrous filters marks a groundbreaking milestone in the field of low-pressure filtration.

This work was supported by a Polish-Swiss grant NANOSORP PSPB-209/2010. Authors thank Pawel Kmuk from Amazon Filters Sp. z o.o. for his help during the filter production process.

\title{
SYMBOLS
}

\author{
$c_{P E} \quad$ unit price energy, $\$ / \mathrm{kWh}$ \\ $m \quad$ ratio of the costs of water pumping through modified $(\mathrm{PP}+\mathrm{ZnO}+\mathrm{Ag})$ and non-modified \\ (PP) filter, - \\ $M \quad$ main operating cost, $\$$ \\ $\Delta p \quad$ momentary pressure drop across the filter, $\mathrm{Pa}$ \\ $Q \quad$ flow rate, $\mathrm{m}^{3} / \mathrm{h}$ \\ $t \quad$ time, h \\ $t_{F} \quad$ filtration time, $\mathrm{h}$ \\ Greek symbols \\ $\eta_{p} \quad$ mechanical efficiency of the pump, - \\ Superscripts \\ $P P \quad$ filter made of polypropylene \\ $P P+Z n O+A g$ filter made of polypropylene with $\mathrm{ZnO}$ and $\mathrm{Ag}$ nanoparticles
}

\section{REFERENCES}

Andrade P.F., de Faria A.F., Oliveira S.R., Arruda M.A.Z., do Carmo Gonçalves M., 2015. Improved antibacterial activity of nanofiltration polysulfone membranes modified with silver nanoparticles. Water Res., 81, 333-342. DOI: 10.1016/j.watres.2015.05.006.

Berg H.C., 1975. Bacterial behaviour. Nature, 254, 389-392. DOI: 10.1038/254389a0.

Bodasinski J., Gradon J., Kmuk P., Ruminski W., 2015. Composite filters structures and method of obtaining the composite filters structures. Patent EP2665583BI.

Camper A.K., LeChevallier M.W., Broadaway S.C., McFeters G.A., 1985. Growth and persistence of pathogens on granular activated carbon filters. Appl. Environ. Microbiol., 50 (6): 1378-1382.

Gac J., Gradon L., 2015. Towards a numerical model of bacterial filtration in fibrous filters. Chem. Process Eng., 36, 89-99. DOI: 10.1515/cpe-2015-0007.

Gradon L., Podgorski A., Balazy A., 2005. Filtration of nanoparticles in the nanofibrous filters. FILTECH EUROPE 2005, 5, 178-185.

Lazarova V., Manem J., 1995. Biofilm characterization and activity analysis in water and wastewater treatment. Water Res., 29, 2227-2245. DOI: 10.1016/0043-1354(95)00054-O.

Mg Y.H., Leung Y.H., Liu F.Z., Ng A.M.C., Gao M.H., Chan C.M.N., Djurisic A.B., Leung F.C.C., Chan W.K., 2013. Antibacterial activity of $\mathrm{ZnO}$ nanoparticles under ambient illumination - The effect of nanoparticle properties. Thin Solid Films, 542, 368-372. DOI: 10.1016/j.tsf.2013.05.167.

Nowak B., Bojarska M., Skowronski J., Piatkiewicz W., 2014. Antibacterial and antifouling properties of polypropylene membranes modified with zinc oxide nanowires, In: Konieczny K., Korus I. (Eds.), Membranes and Membrane Processes in Environmental Protection. Monograph of the Environmental Engineering Committee. Polish Academy of Sciences, Warsaw-Gliwice, 118, 209-220. 
Ochi J., Vernoux J.F., 1999. A two-dimensional network model to simulate permeability decrease under hydrodynamic effect of particle release and capture. Transp. Porous Media, 37, 303-325. DOI: 10.1023/A: 1006690700000.

Ong Y.L., Razatos A., Georgiou G., Sharma M.M., 1999. Adhesion forces between E. coli bacteria and biomaterial surfaces. Langmuir, 15, 2719-2725. DOI 10.1021/la981104e.

Podgorski A., Balazy A., Gradon L., 2006. Application of nanofibers to improve the filtration efficiency of the most penetrating aerosol particles in fibrous filters. Chem. Eng. Sci., 61, 6804-6815. DOI: 10.1016/j.ces.2006.07.022.

Selomulya C., Jia X., Williams R.A., 2005. Direct prediction of structure and permeability of flocculated structures and sediments using 3D tomographic imaging. Chem. Eng. Res. Des., 83 (A7), 844-852. DOI: 10.1205/Cherd.04330.

Tien C., 2012. Principles of filtration. Elsevier, Oxford, U.K.

Tien C., Ramarao B.V., 2011. Granular filtration of aerosols and hydrosols. Elsevier, Oxford, U.K.

USEPA, 2004. Guidelines for Water Reuse. Washington DC.

Van der Merwe R., Hammes F., Lattermann S., Amy G., 2014. Flow cytometric assessment of microbial abundance in the near-field area of seawater reverse osmosis concentrate discharge. Desalination, 343, $208-216$. DOI: 10.1016/j.desal.2014.01.017.

Williams C.J., Edyvean R.G.J., 1998. An investigation into the filtration of biological materials: Why is it such a problem?. Filtr. Sep., 33, 507-512. DOI: 10.1016/S0015-1882(98)80025-6.

You J., Zhang Y., Hu Z., 2011. Bacteria and bacteriophage inactivation by silver and zinc oxide nanoparticles. Colloids Surf. B, 85, 161-167. DOI: 10.1016/j.colsurfb.2011.02.023.

Received 17 March 2016

Received in revised form 09 May 2016

Accepted 20 June 2016 